\title{
Identification of mink (Neovison vison) fecal proteins during embryonic diapause and placental pregnancy for non-invasive pregnancy diagnosis in wildlife
}

\author{
E Curry ${ }^{1}$, JS Easley ${ }^{2}$, J Wojtusik ${ }^{1}$ and TL Roth ${ }^{1}$ \\ ${ }^{1}$ Center for Conservation and Research of Endangered Wildlife, Cincinnati Zoo \& Botanical \\ Garden, Cincinnati, OH, USA \\ ${ }^{2}$ Fur Commission, USA
}

Corresponding author email: erin.curry@cincinnatizoo.org

\begin{abstract}
Currently, there is no method to diagnose pregnancy non-invasively in most wildlife species that experience delayed implantation and pseudopregnancy, either during embryonic diapause or placental pregnancy. The aim of this study was to utilize farmraised mink (Neovison vison) as a model species to evaluate changes in the fecal proteome associated with pregnancy. Specific objectives were to: 1) determine if fecal peptides were differentially abundant in parturient versus non-parturient mink and; 2 ) identify proteins of interest. Samples $(n=12)$ were selected retrospectively from mink $(n=6)$ that were parturient $(n=3)$ or non-parturient $(n=3)$ and were collected from parturient females during embryonic diapause and placental pregnancy or, on the same calendar dates from non-parturient females. Following protein extraction, twodimensional differential in-gel electrophoresis was utilized to assess differences in protein spot abundance among samples. The mean number of spots per gel was $2107 \pm 62.2$ and spots meeting specific criteria (student's t-test; $P<0.10 ;>2.5$ fold change between groups) were selected for identification via matrix-assisted laser desorption/ ionization- time-of-flight mass spectrometry. During diapause, six spots (angiotensinconverting enzyme 2, interleukin-36 receptor antagonist, carboxypeptidase A1 (two spots), carboxypeptidase A2, and chymotrypsin-like protease CTRL-1) were higher in parturient and one spot (intestinal fatty acid-binding protein) was higher in nonparturient. During placental pregnancy, seven spots (cytosol aminopeptidase (three spots), calcium-activated chloride channel regulator 1 , carboxypeptidase A1 (two spots), and chymotrypsin) were higher in parturient and two (ovalbumin and protein PRR14L) were higher in non-parturient. This is the first description of the mink fecal proteome related to pregnancy and of changes in specific fecal proteins during embryonic diapause in any species.
\end{abstract}

\section{Introduction}

Reproductive monitoring of many wildlife species is hindered by the lack of an accurate, noninvasive means to diagnose pregnancy. In some species, including those in the Mustelidae and Ursidae families, reproductive diagnostics are further complicated due to two distinct phases of gestation, embryonic diapause and placental pregnancy, as well as the occurrence of pseudopregnancy [1] [2] [3] [4] [5]. For species maintained in zoological institutions, the ability to detect and monitor gestation is essential for optimal management and also may help to illuminate the point of reproductive malfunction in individuals that breed but fail to produce offspring. 
Although pregnancy-specific serum proteins have been described in some mammals, including humans [6], mice [7], sheep [8], and horses [9], the physical or chemical restraint of many nondomestic species for blood collection is unwarranted, as it may elicit an adverse stress response in a potentially pregnant female. In zoos, there are increasing efforts to condition individual animals for voluntary blood collection [10], but training such behaviors is time-consuming, requires appropriate facility modifications such as a blood sleeve or access port, and necessitates that animal care staff themselves receive instruction in operant conditioning techniques and venipuncture; therefore, serum analyses for pregnancy diagnosis is unlikely to be broadly applicable across species in all zoological settings. Fortunately, the collection of feces is feasible in most non-domestic species, tends to provide sufficient sample mass, and frequent sampling can be achieved with minimal disruption to daily husbandry routines. Consequently, non-invasive fecal steroid metabolite analysis has become the benchmark for monitoring reproductive processes in intractable wildlife species [11]; however, when attempting to assess reproductive status in some species, especially those that experience embryonic diapause and pseudopregnancies, the information gained from steroid metabolite patterns is limited in value. For example, in five bear species as well as red pandas (Ailurus fulgens), efforts to detect pregnancy using traditional methods have shown that fecal steroid metabolites are ineffective in distinguishing pregnancy from pseudopregnancy [5] [12] [13] [14].

Accordingly, there is growing interest in the discovery of non-traditional fecal biomarkers, such as proteins or protein fragments, which may be useful in broadening our insight into true pregnancy status. Whereas there are hundreds of reports detailing fecal proteins associated with colorectal cancer (as reviewed by [15]) and other gastrointestinal disorders [16] [17], few reports describe changes in specific fecal proteins associated with pregnancy in any species. Two recent papers reported differences in abundance of several proteins found in fecal samples of pregnant versus nonpregnant polar bears [18] and cheetahs [19], but none have investigated fecal biomarkers during embryonic diapause. Performing biomarker discovery studies on zoo-housed animals is confounded by the challenges in executing well-controlled scientific studies. Zoo animals represent heterogenous populations and identifying a statistically sound cohort of age-matched individuals with similar life histories and subject to the same environmental conditions, medical care, and diets is unachievable. Therefore, our aim was to use a controlled population of farm-raised mink (Neovison vison) as a model species to evaluate potential biomarkers of the fecal proteome associated with pregnancy during embryonic diapause and placental pregnancy. Specific objectives were to: 1) determine if abundance of specific peptides or peptide fragments differed in the feces of parturient versus non-parturient mink during the two distinct phases of pregnancy and; 2 ) identify the proteins of interest. Evaluating peptides and proteins excreted in feces may provide insight into pregnancy status.

\section{Materials and methods}

\section{Animals}

Fecal samples ( $n=12$ ) were collected from black color phase mink (Neovison vison; $n=6$ ) maintained on a commercial fur farm (Wisconsin, USA) and housed individually. No changes to diet or husbandry were implemented for the purposes of this study. Major dietary components included salmon, chicken, turkey, and cheese and the macronutrient ratio was $45 \%$ protein, $20 \%$ fat, and $12 \%$ carbohydrates. The diet was finely ground and well mixed. Of the six animals, five females were mated three times each between 6 March and 17 March and the sixth female did not breed. Animals were subject to natural photoperiod until the end of breeding, after which the photoperiod was extended by two hours until just before whelping. Parturient females $(n=3)$ were 
confirmed by the birth of kits whereas non-parturient females $(n=3)$ did not produce kits. The mean whelping date and litter size were $30 \mathrm{April}( \pm 0.3 \mathrm{~d}$ ) and 5.3 ( \pm 0.7 kits), respectively.

Fresh fecal samples were collected from all females on 26 March, when the parturient females would have embryos in diapause, and 13 April (18 days pre-partum), during placental pregnancy. Samples were collected on the same calendar dates from non-parturient females. Fecals were collected from under individual cages, placed in individual ziplock baggies labelled with the animal ID and the date, and stored at $-20^{\circ} \mathrm{C}$ until analysis.

\section{Protein extraction}

A commercial service provider (Applied Biomics, Inc; Hayward, CA, USA) was sourced to extract protein from frozen fecal samples. To minimize proteins of bacterial origin, an extraction method was utilized which avoided the disruption of bacterial cell membranes. Briefly, approximately $5 \mathrm{mg}$ of frozen feces from each sample was resuspended in $10 \mathrm{~mL}$ phosphate buffered saline (PBS) containing protease inhibitor and subjected to gentle agitation for $30 \mathrm{~min}$. The mixture was centrifuged for 4000 RPM for 20 min to remove fibrous material. The supernatant was removed and protein concentrated due to standardized laboratory protocols. Protein was subject to the Bradford assay (Bio-Rad; Hercules, CA, USA) to determine sample protein concentration.

\section{D-DIGE and MS}

Two-dimensional differential in-gel electrophoresis (2D-DIGE) and mass spectrometry (MS) were performed by Applied Biomics to identify proteins differing in abundance in the feces of parturient mink when compared to non-parturient mink. Protein samples were precipitated by methanol and then resuspended in 2-D cell lysis buffer $(30 \mathrm{mM}$ Tris- $\mathrm{HCl}$, pH 8.8, containing $7 \mathrm{M}$ urea, $2 \mathrm{M}$ thiourea and 4\% 3-[(3-cholamidopropyl)dimethylammonio]-1-propanesulfonate (CHAPS). For each sample, $30 \mu \mathrm{g}$ of protein was mixed with $1.0 \mathrm{ul}$ of diluted CyDye fluor and kept in the dark on ice for $30 \mathrm{~min}$. The labelling reaction was stopped by the addition of $1.0 \mu \mathrm{l}$ of $10 \mathrm{mM}$ lysine to each sample and incubating in the dark on ice for an additional $15 \mathrm{~min}$. The labelled samples were then mixed together and 2X 2-D sample buffer ( $8 \mathrm{M}$ urea, 4\% CHAPS, $20 \mathrm{mg} / \mathrm{ml} \mathrm{DTT}, 2 \%$ pharmalytes and trace amount of bromophenol blue), $100 \mu$ destreak solution and rehydration buffer ( $7 \mathrm{M}$ urea, $2 \mathrm{M}$

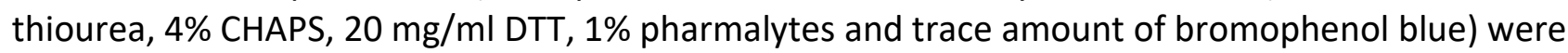
added to the labelling mix to bring the total volume to $250 \mu \mathrm{l}$. The samples were mixed and centrifuged before loading into the strip holder.

Six analytical gels $(18 \times 16 \mathrm{~cm}$ ) were performed to compare equal amounts ( $30 \mu \mathrm{g} /$ individual) of protein extracts from parturient and non-parturient females along with an internal standard. Samples were labeled with Cy3 or Cy2 dyes with dye swap across samples, and the internal standard was labeled with Cy5. One sample from each of the timepoints were combined by date and separated by 2D-gel electrophoresis on six gels total. Following electrophoresis, the gels were scanned using Typhoon TRIO (Amersham BioSciences; Piscataway, NJ, USA) and analyzed with ImageQuant software (Molecular Dynamics, Sunnyvale, CA, USA). The standardization and statistical analysis of protein volumes were carried out using the biological variation analysis (BVA) module of the DeCyder software (v.6.5, GE Healthcare). The use of the internal control effectively removes system variation enabling accurate quantitation of changes among samples. Comparisons of normalized protein abundances were made within each timepoint between the parturient and non-parturient individuals using Student's $t$ test.

A total of 150 spots displayed different abundance between groups according to the service provider's criteria (Student's $t$ test; P-value $<0.1$; fold changes greater than 1.5 ); however, to narrow down targets with likelihood of displaying unambiguous divergences in protein 
concentrations between groups, more rigorous criteria were implemented: 1) fold change of $>2.5$ between groups; 2 ) spot volume must be numerically higher in all individual samples of a desired group compared to the others, and; 3 ) standard deviations cannot overlap. Fifteen individual spots met these conditions and were dissected from the gel using an Ettan spot picker (Amersham Biosciences). Dissected spots were then trypsin digested, desalted, and submitted for matrixassisted laser desorption/ionization- time-of-flight (MALDI-TOF) analysis. Proteins were identified by peptide mass fingerprinting using the MASCOT search engine (http://www.matrixscience.com; Matrix Science, Inc., Boston, MA, USA) and compared to NCBI database in February 2019 to identify proteins, including that of the mink (Neovison vison). Candidates with a total ion confidence interval of greater than $97.0 \%$ were accepted as positive identification. All averages are presented as mean \pm standard deviation.

\section{Results and Discussion}

The number of spots that resolved on each gel ranged from 1874 to 2302 ( $2107 \pm 62$.2; Figure 1$)$. Protein identities were obtained for 15 individual spots of interest (Table 1). All peptide sequences matched to the mink database with high confidence (>97\%), with the exception of spot 103 (Ovalbumin), an avian protein which likely originated from chicken eggs provided in the diet. Overall, the 15 spots corresponded to 10 unique proteins.

During diapause, six spots corresponding to five proteins (angiotensin-converting enzyme 2 (ACE2), interleukin-36 receptor antagonist (IL36RA), carboxypeptidase A1 (CPA1; two spots), carboxypeptidase A2 (CPA2), and chymotrypsin-like protease CTRL1 (CTRL1)) were higher in parturient and one spot (intestinal fatty acid-binding protein (FABP2)) was higher in non-parturient (Figure 2). During placental pregnancy, seven spots corresponding to four proteins (cytosol aminopeptidase (LAP3; three spots), calcium-activated chloride channel regulator 1 (CLCA1), CPA1 (two spots), and CTRL) were higher in parturient and two (OVAL, PRR14) were higher in nonparturient. Two spots, CPA1 and CTRL1, were upregulated at both timepoints in parturient females.

Although none of these proteins has been identified previously as a marker unique to pregnancy, many are involved in processes required to maintain pregnancy. Carboxypeptidases $A 1$ and $A 2$ (CPA1 and CPA2) were found to be significantly higher in parturient females during embryonic diapause and, moreover, CPA1 also was increased during placental pregnancy. The carboxypeptidase A and B subfamilies, produced by the pancreas, are involved in breaking down and digesting peptides [20]. In particular, CPA aids in the absorption of four essential amino acids, valine, leucine, isoleucine, and phenylalanine, which cannot be endogenously synthesized [21]. Recent metabolomics analyses of uterine flushes of European roe deer (Capreolus capreolus) during diapause revealed increases in valine as developmental stage progressed [22] and preliminary analyses of serum collected from pregnant Weddel seals (Leptonychotes weddellii) showed increases in circulating valine, leucine, and isoleucine [23]. Although CPA has not been described to have a direct role in pregnancy, another carboxypeptidase, CPB, was determined to be more abundant in fecal samples collected from pregnant versus pseudopregnant polar bears by our lab using similar methodologies [18]. Enhanced production of pancreatic carboxypeptidases may be a direct reflection of increased requirements for absorption of specific amino acids during embryonic diapause and placental pregnancy. 


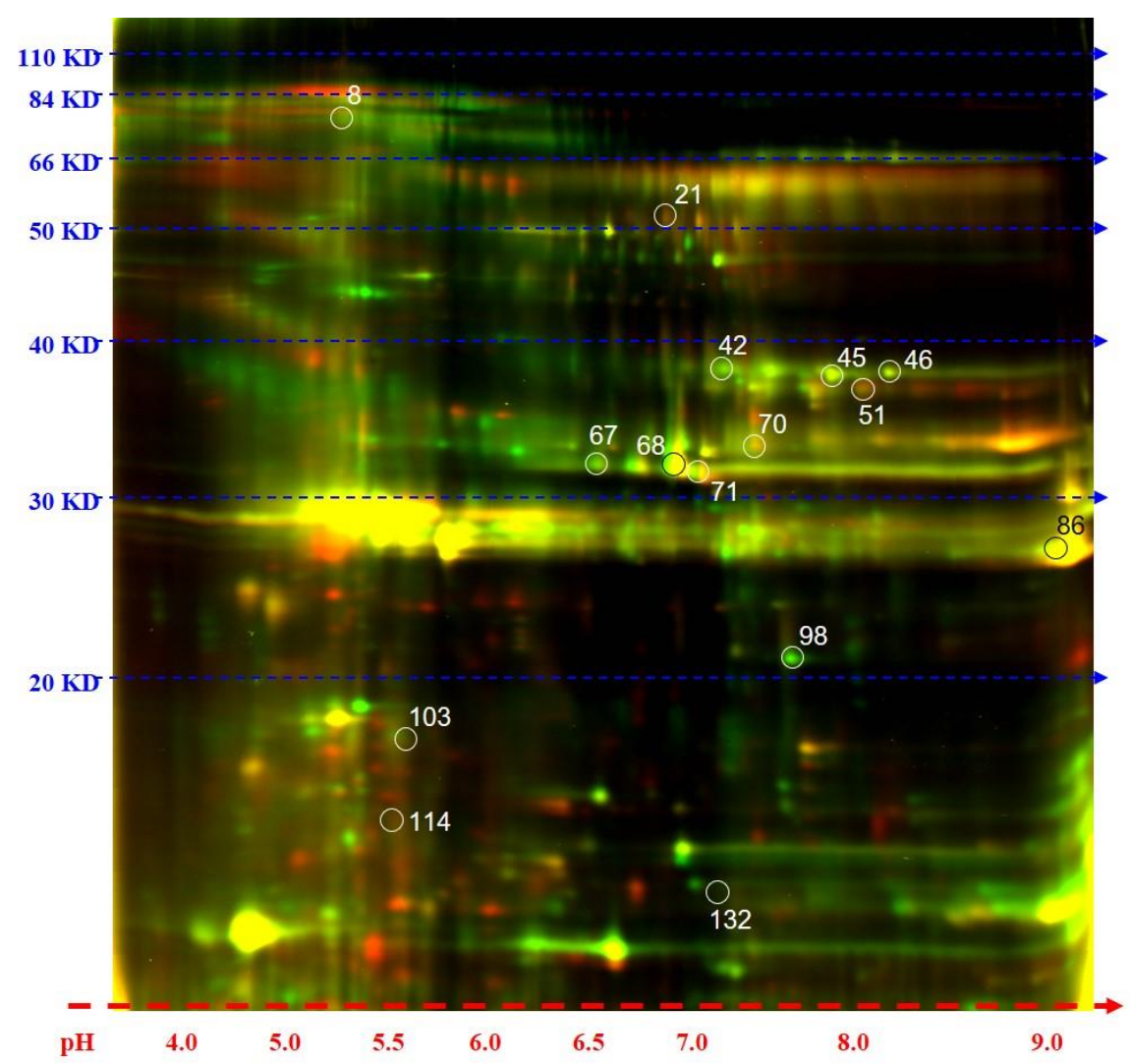

Figure 1. Representative image of 2D-DIGE analytical gel showing mink fecal proteins separated by $\mathrm{pH}$ gradient (x-axis) and molecular weight (y-axis). A total of 15 spots (approximate positions indicated with circles) were dissected from the gel and subject to mass spectrometry analyses.

A protein more abundant in the fecal samples of parturient females, calcium-activated chloride channel regulator 1 (CLCA1), was also identified previously by our lab as a candidate protein of interest [18]. Although literature describing this protein's function is scant, calcium-activated chloride channels (CaCCs) are involved in a range of processes, including olfactory and taste transduction, neuronal and cardiac excitability, among others [24]. Additionally, CaCCs are involved in fluid secretion by intestinal epithelium and the pancreas [24] and a recent report [25] described the role of CLCA1 in regulating intestinal mucous by mediating expansion of the inner mucus layer, which provides a protective barrier against bacteria [26]. It is plausible that the increase in CLCA1 detected in both pregnant polar bears and mink may serve to confer enhanced immunity during pregnancy. Alternately, it may be an artifact of increased pancreatic function, consistent with the increases in pancreatic enzymes (CPA1 and CPA2) also observed. 
Table 1. Identities of protein spots of interest, including names, abbreviations, NCBI accession number, P-value(s), fold change (relative to non-parturient), confidence interval at which they were identified, molecular weight of total protein (MW; kD) and isoelectric point ( $\mathrm{pl}$ ).

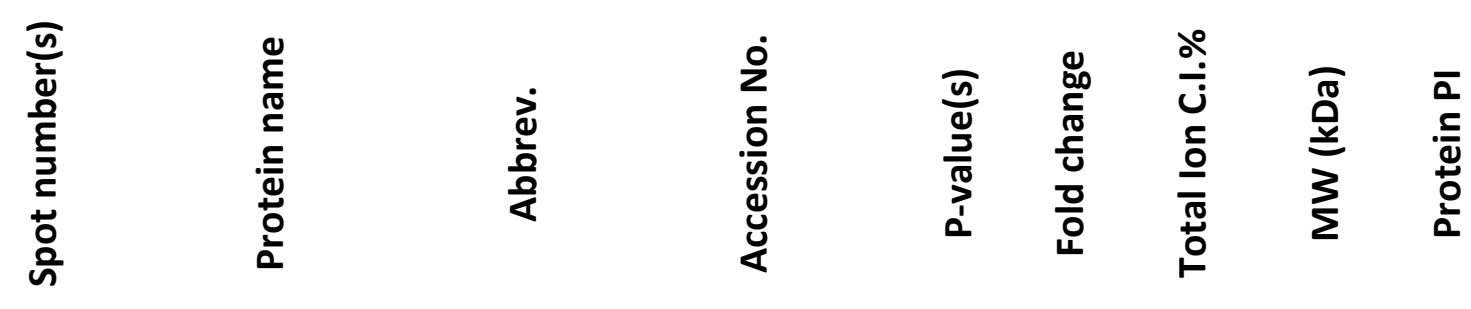

\begin{tabular}{|c|c|c|c|c|c|c|c|c|}
\hline 8 & $\begin{array}{c}\text { Angiotensin- } \\
\text { converting } \\
\text { enzyme } 2, \text { partial }\end{array}$ & ACE2 & gi|1064617951 & 0.07 & 4.2 & 99.6 & 54.5 & 6.06 \\
\hline 21 & $\begin{array}{l}\text { Interleukin-36 } \\
\text { receptor } \\
\text { antagonist } \\
\text { protein }\end{array}$ & IL36RA & gi|1064628607 & 0.03 & 3.0 & 97.8 & 16.9 & 4.98 \\
\hline 42 & \multirow{3}{*}{$\begin{array}{c}\text { Cytosol } \\
\text { aminopeptidase }\end{array}$} & \multirow{3}{*}{ LAP3 } & \multirow{3}{*}{ gi|1064643245 } & 0.09 & 3.8 & \multirow{3}{*}{100.0} & \multirow{3}{*}{56.1} & \multirow{3}{*}{6.81} \\
\hline 45 & & & & 0.06 & 6.4 & & & \\
\hline 46 & & & & 0.03 & 3.4 & & & \\
\hline 51 & $\begin{array}{l}\text { Calcium-activated } \\
\text { chloride channel } \\
\text { regulator } 1\end{array}$ & CLCA1 & gi|1064644985 & 0.09 & 3.4 & 100.0 & 99.4 & 6.67 \\
\hline 67 & \multirow{4}{*}{$\begin{array}{c}\text { Carboxypeptidase } \\
\text { A1 (pancreatic), } \\
\text { partial }\end{array}$} & \multirow{4}{*}{ CPA1 } & \multirow{4}{*}{ gi|1064617379 } & 0.01 & 3.3 & \multirow{4}{*}{100.0} & \multirow{4}{*}{15.8} & \multirow{4}{*}{9.16} \\
\hline 68 & & & & 0.10 & 4.1 & & & \\
\hline 71 & & & & 0.08 & 3.5 & & & \\
\hline 98 & & & & 0.03 & 3.5 & & & \\
\hline 70 & $\begin{array}{l}\text { Carboxypeptidase } \\
\text { A2, partial }\end{array}$ & CPA2 & gi|1064616759 & 0.04 & 4.2 & 100.0 & 27.5 & 8.54 \\
\hline \multirow[t]{2}{*}{86} & $\begin{array}{l}\text { Chymotrypsin- } \\
\text { like protease }\end{array}$ & \multirow[t]{2}{*}{ CTRL1 } & \multirow[t]{2}{*}{ gi|1064621357 } & 0.00 & 2.5 & \multirow[t]{2}{*}{100.0} & \multirow[t]{2}{*}{16.7} & \multirow[t]{2}{*}{9.33} \\
\hline & CTRL-1, partial & & & 0.09 & 3.6 & & & \\
\hline 103 & Ovalbumin & OVAL & OVAL_CHICK & 0.08 & -5.8 & 100.0 & 42.9 & 5.19 \\
\hline 114 & $\begin{array}{l}\text { Proline rich } \\
\text { repeat } 14 \text {-like }\end{array}$ & PRR14L & gi|1064641949 & 0.00 & -3.5 & 97.9 & 234.9 & 5.62 \\
\hline 132 & $\begin{array}{l}\text { Fatty acid-binding } \\
\text { protein, intestinal }\end{array}$ & FABP2 & gi|1064644869 & 0.08 & -3.5 & 100.0 & 15.0 & 7.88 \\
\hline
\end{tabular}

Cytosol aminopeptidase, also called leucine aminopeptidase 3 (LAP3), was represented by three different spots that were more abundant in the parturient group during placental pregnancy. Aminopeptidase activity was higher in the serum of pregnant primates [27] and LAP3 specifically was higher in twin vs. singleton pregnancies in humans [28], rendering it a promising candidate for 

107

future studies. Chymotrypsin-like protease 1 (CTRL1) was higher at both timepoints in parturient females. CTRL1, a serine protease, has been identified in pancreatic homogenate, duodenal fluids, and urine [29]. Other serine proteases have been implicated in pregnancy, being produced by the placenta [30] [31] or endometrial gland during the implantation period [32]; however, a role of CTRL1 during pregnancy has not yet been established.

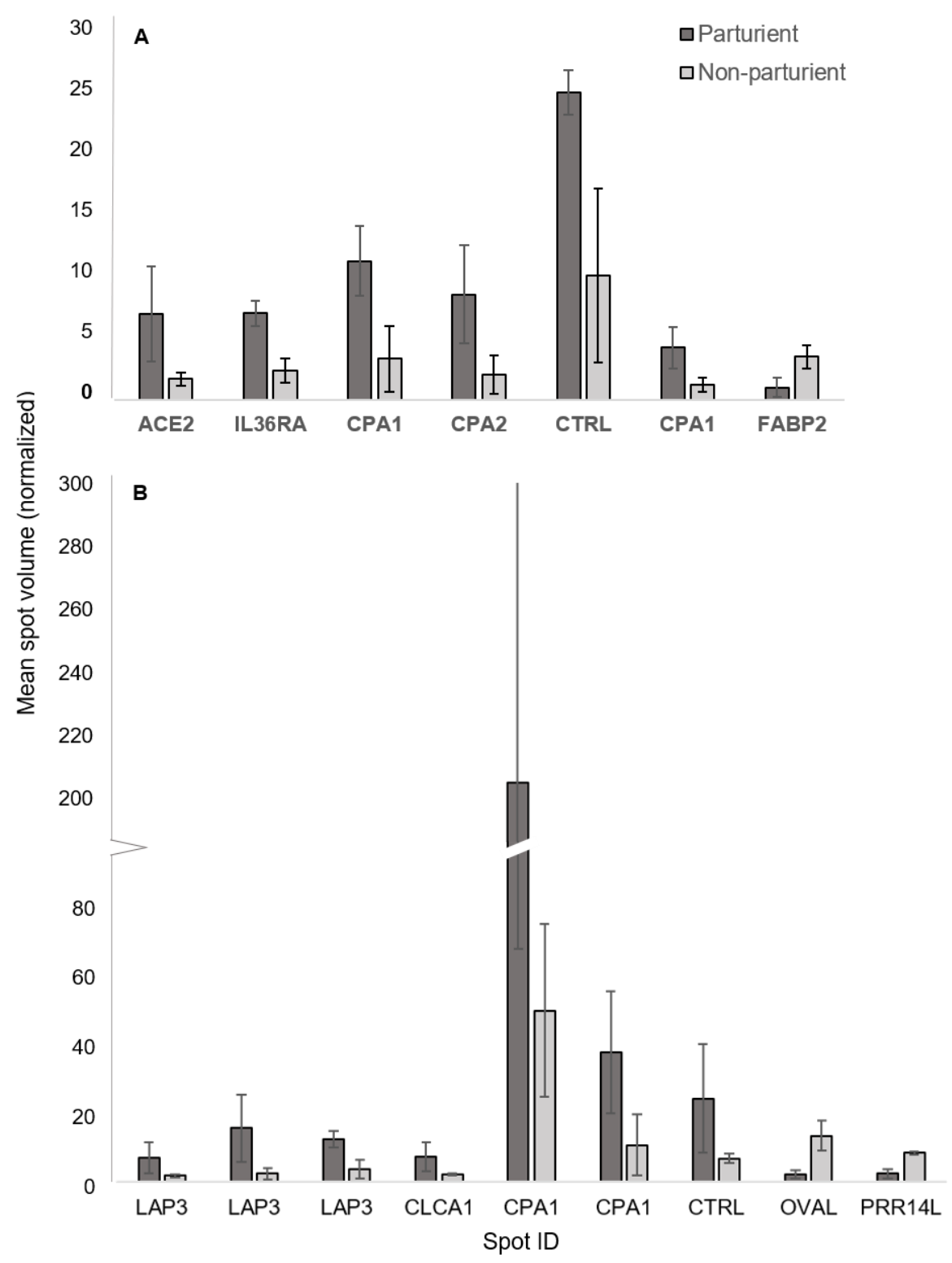

Figure 2. Differentially abundant protein spots during embryonic diapause (panel A) and placental pregnancy (panel B) for parturient mink (dark bar) and equivalent time points for non-parturient mink (light bar). Each bar represents the mean spot volume of 3 samples collected from either parturient (dark bar) or nonparturient (light bar) individuals. Error bars denote standard deviation from the mean.

Angiotensin-converting enzyme 2 (ACE2) was higher during diapause, but not placental pregnancy. ACE2 is a cell surface glycoprotein which converts vasoconstrictive angiotensin (Ang II) to its vasodilatory form (Ang-(1-7)) [33]. In addition to vasodilation, Ang-(1-7) also modulates blood vessel growth and angiogenesis of the uteroplacental unit [34]. In rats, expression of ACE2 was increased during pregnancy, with the highest contributors being placenta and uterus [35] and, in humans, it was expressed in the trophoblast and the maternal decidual cells [34]. The authors postulated that ACE2 may influence the luminal side of uterine decidual veins and adjacent 
arteries. It is possible that, in species that experience delayed implantation, ACE2 modulates uterine vasculature remodelling prior to embryo implantation, so expression would be higher in early pregnancy.

Interleukin-36 receptor antagonist protein (IL36RA) was higher during diapause. The IL-36 cytokines, a subfamily of the IL-1 superfamily, promote induction of various inflammatory mediators and activate a pathway which results in expression of inflammatory cytokines [36]. In contrast, IL36RA inhibits this process by binding to the IL-36 receptor and inducing dimerization. IL36 cytokines are expressed in the human and mouse uteri [37] and are localized in the uterine luminal and glandular epithelia [36]. High levels of IL-36 cytokines were found to be associated with enhanced inflammatory activity and high fetal resorption in mice [38] and IL36RA was expressed by the placenta at lower levels in patients with preeclampsia compared to normal pregnancies [39]. Taken together, it seems likely that IL36RA may contribute to the regulatory immune milieu of the uterus during the pre-implantation period.

Only three spots were lower in abundance in samples collected from parturient females compared to the non-parturient. Ovalbumin (OVAL) is of dietary origin; it was confirmed that eggs were included in the diets offered to the study animals. An increase in nutrient absorption by pregnant females may explain the increased abundance of OVAL excreted by the non-parturient group. Fatty acid-binding protein (FABP2) was lower in the feces of parturient females during diapause, but not placental pregnancy. This protein is produced by the enterocytes of the small intestines, suggesting a role in absorption [40], and additionally has been shown to be involved in the intracellular transport of dietary long-chain fatty acids [41]. As with several of the other proteins described, the differences observed likely are due to unique nutrient absorption needs during pregnancy. Finally, Proline rich repeat 14-like protein (PRR14L) was lower during placental pregnancy. Literature characterizing the PRR14L protein is scarce and, at the time of writing, its function has not been described [42]; therefore, its relationship to gestation remains to be determined.

As has been reported in other studies, it is not surprising that a protein biomarker unique to pregnancy was not identified; however, it seems that specific fecal proteins may differ in abundance in association with pregnancy. It is conceivable that other peptides were different between groups, but eluded detection by the techniques utilized in this study. A limitation of 2DDIGE analysis is the inability to resolve spots less than seven $\mathrm{kDa}$ in size, so smaller proteins may be below the detection limit. In addition, other proteins may have been lost during extraction. Although some proteins, such as calprotectin, are stable in feces over time [43], it is likely that others were degraded by proteolytic enzymes prior to excretion, acquisition and/or processing.

In conclusion, this study utilized 2D-DIGE/ MS analysis to identify proteins that were significantly different in abundance in the feces of parturient mink when compared to non-parturient during both embryonic diapause and placental pregnancy. To our knowledge, this is the first study that utilized 2D-DIGE to identify differentially expressed proteins in fecal samples collected during embryonic diapause for use as a pregnancy marker in any species. At both pregnancy stages, proteins were identified that differed in abundance between parturient and non-parturient groups, thereby establishing a list of candidate biomarkers that may be useful in the advancement of reproductive diagnostics of wildlife species, particularly those that experience delayed implantation and pseudopregnancy. 


\section{Declaration of interest}

The authors declare that there is no conflict of interest that could be perceived as prejudicing the impartiality of this article.

\section{Funding}

This project was made possible in part by the Institute of Museum and Library Services grant \#MA30-18-0461-18 and by CREW's Polar Bear Challenge. The authors thank generous supporters, including the Haas Family, Dave \& Debbie Horn, and the Young Family Foundation.

\section{Acknowledgements}

The authors thank CREW Research Associate, Elizabeth Donelan, and the CREW endocrine lab volunteers, especially Robin Anslinger and Carol Wehman, who contributed to sample inventorying and processing.

\section{References}

[1] Tsubota T, Takahashi Y and Kanagawa H. 1987 Changes in serum progesterone levels and growth of fetuses in Hokkaido brown bears. International Conference on Bear Research and Management 7 355-358.

[2] Schulz L, Nelson R, Pyter L and Bahr JM. 2003 Induction of pseudopregnancy in the American black bear (Ursus americanus). Journal of Experimental Zoology 298 162-166.

[3] Sato M, Tsubota T, Komatsu T, Watanabe G, Taya K, Murase T, Kita I and Kudo T. 2001 Changes in sex steroids, gonadotropins, prolactin, and inhibin in pregnant and nonpregnant Japanese black bears (Ursus thibetanus japonicus). Biology of Reproduction 65 1006-1013.

[4] Tsubota T, Kanagawa H, Yamamoto K, Mano T, Yamanaka M, Kita I and Tiba T. 1992 Serum progesterone concentrations using P-EIA kit in captive and free-ranging Hokkaido brown bears (Ursus arctos yesoensis). Journal of Veterinary Medical Science 54 1-5.

[5] Schwarzenberger F, Fredriksson G, Schaller K and Kolter L. 2004 Fecal steroid analysis for monitoring reproduction in the sun bear (Helarctos malayanus). Theriogenology 62 1677-92.

[6] Saxena B, Hasan S, Haour F and Schmidt-Gollwitzer M. 1974 Radioreceptor assay of human chorionic gonadotropin: detection of early pregnancy. Science 184 793-795.

[7] Lin T, Halbert S and Kiefer D. 1974 Pregnancy-associated serum protein antigens in the rat and mouse. Proceedings of the Society for Experimental Biology and Medicine 145 62-66.

[8] Staples L. 1980 Isolation and partial characterization of an antigen associated with pregnancy in the ewe. Biology of Reproduction 22 675-680.

[9] Cole H and Hart G. 1930 The potency of blood serum of mares in progressive stages of pregnancy in effecting the sexual maturity of the immature rat. American Journal of Physiology 93 57-68.

[10] Otaki Y, Kido N, Omiya T, Ono K, Ueda M, Azumano A and Tanaka S. 2015 A new voluntary blood collection method for the Andean bear (Tremarctos ornatus) and Asiatic black bear (Ursus thibetanus). Zoo Biology 34 497-500.

[11] Schwarzenberger F. 2007 The many uses of non-invasive faecal steroid monitoring in zoo and wildlife species. International Zoo Yearbook 41 52-74.

[12] Dehnhard M, Hildebrandt T, Knauf T, Jewgenow K, Kolter L and Goritz F. 2006 Comparative endocrine investigations in three bear species based on urinary steroid metabolites and volatiles. Theriogenology 66 1755-1761.

[13] Stoops MA, MacKinnon K and Roth TL. 2012 Longitudinal fecal hormone analysis for monitoring reproductive activity in the female polar bear (Ursus maritimus). Theriogenology 78 1977-1986. 
[14] Curry E, Browning L, Reinhart P and Roth TL. 2017 Integrating trans-abdominal ultrasonography with fecal steroid metabolite monitoring to accurately diagnose pregnancy and predict the timing of parturition in the red panda (Ailurus fulgens styani). Zoo Biology 36 193-200.

[15] Ang C, Phung J and Nice E. 2011 The discovery and validation of colorectal cancer biomarkers. Biomedical Chromatography 25 82-89.

[16] Poullis A, Foster R, Northfield T and Mendall M. 2002 Review articles: faecal markers in the assessment of activity in inflammatory bowel disease. Alimentary Pharmacology \& Therapeutics 16 675-681.

[17] Levin B, Brooks D, Smith R and Stone A. 2003 Emerging technologies in screening for colorectal cancer: $\mathrm{CT}$ colonography, immunochemical fecal occult blood tests, and stool screening using molecular markers. CA: A Cancer Journal for Clinicians 53 44-55.

[18] Curry E, Stoops MA and Roth TL. 2012 Non-invasive detection of candidate pregnancy protein biomarkers in the feces of captive polar bears (Ursus maritimus). Theriogenology 78 308-314.

[19] Koester D, Wildt D, Maly M, Comizzoli P and Crosier A. 2017 Non-invasive identification of protein biomarkers for early pregnancy diagnosis in the cheetah (Acinonyx jubatus). PLOS ONE 12 1-21.

[20] Reznik S and Fricker L. 2001 Carboxypeptidases from A to Z: implications in embryonic development and Wnt binding Cellular and Molecular Life Sciences 58 1790-1804.

[21] Hooper N. 1996 Zinc Metalloproteases In Health And Disease, London, UK:CRC Press.

[22] Van der Weijden V, Ruegg A, Giesbertz P, Daniel H, Drews B and Ulbrich S. 2019 Uterine fluid amino acids and acylcarnitines indicate metabolic activity in European roe deer (Capreolus capreolus) embryos during diapause. Third International Symposium on Embryonic Diapause, Ascona, Switzerland.

[23] Shero M. 2019 If all Pinniped species are supposed to have embryonic diapause, then why might not this one? Third International Symposium on Embryonic Diapause, Ascona, Switzerland.

[24] Hartzell C, Putzier I and Arreola J. 2005 Calcium-activated chloride channels. Annual Reviews in Physiology 67 719-758.

[25] Nystrom E, Birchenough G, van der Post S, Arike L, Gruber A, Hansson G and Johansson M. 2018 Calcium-activated chloride channel regulator 1 (CLCA1) controls mucus expansion in colon by proteolytic activity. EBioMedicine 33 134-143.

[26] Birchenough G, Nystrom E, Johansson M and Hansson G. 2016 A sentinel goblet cell guards the colonic crypt by triggering Nirp6-dependent Muc2 secretion. Science 352 1535-1542.

[27] Dracopoli N and Brett F. 1982 Serum aminopeptidases in pregnant vervet monkeys. Biochemical Genetics 20 825-831.

[28] Miller ZB, Naor E, Milkovich L and Schmidt W. 1964 Serum levels of cystine aminopeptidase, leucine aminopeptidase, and alkaline phosphatase in single and twin pregnancies. Obstetrics and Gynecology 24 707-715.

[29] Reseland J, Larsen F, Solheim J, Eriksen J, Hanssen L and Prydz H. 1997 A novel human chymotrypsinlike digestive enzyme. The Journal of Biological Chemistry 272 8099-8104.

[30] Wang Y, Gu Y, Zhang Y, Lewis D, Alexander J and Granger D. 2006 Increased chymotrypsin-like protease (chymase) expression and activity in placentas from women with preeclampsia. Placenta $28263-$ 269.

[31] De Luca A, De Falco M, Fedele V, Cobellis L, Mastrogiacomo A, Laforgia V, Tuduce I, Campioni M, Giraldi D, Paggi M and Baldi A. 2004 The serine protease HtrA1 is upregulated in the human placenta during pregnancy. Journal of Histochemistry \& Cytochemistry 52 885-892.

[32] O'Sullivan C, Liu S, Karpinka J and Rancourt D. 2002 Embryonic hatching enzyme strypsin/ISP1 is expressed with ISP2 in endometrial glands during implantation. Molecular Reproduction and Development 62 328-334.

[33] Bharadwaj M, Strawn W, Groban L, Yamaleyeva L, Chappell M, Horta C, Atkins K, Firmes L, Gurley S and Brosnihan K. 2011 Angiotensin-converting enzyme 2 deficiency is associated with impaired gestational weight gain and fetal growth restriction. Hypertension 58 852-858. 
[34] Valdés G, Neves LA, Anton L, Corthorn J, Chacón C, Germain AM, Merrill DC, Ferrario CM, Sarao R, Penninger J and Brosnihan KB. 2006 Distribution of angiotensin-(1-7) and ACE2 in human placentas of normal and pathological pregnancies. Placenta 27 200-207.

[35] Levy A, Yagil Y, Bursztyn M, Barkalifa R, Scharf S and Yagil C. 2008 ACE2 expression and activity are enhanced during pregnancy. American Journal of Integrative Comparative Physiology 295 1953-1961.

[36] Murrieta-Coxca J, Rodriguez-Martinez S, Cancino-Diaz M, Markert U, Favaro R and Morales-Prieto D. 2019 IL-36 cytokines: regulators of inflammatory responses and their emerging role in immunology of reproduction. International Journal of Molecular Sciences 20 1649-1673.

[37] Busfield S, Comrack C, Yu G, Chickerine T, Smutko J, Zhou H, Leiby K, Holmgren L, Gearing D and Pan Y. 2000 Identification and gene organization of three novel members of the IL-1 family on human chromosome 2.Genomics 66 213-216.

[38] Murrieta-Coxca J, Gomez-Chavez F, Cancino-Diaz M, Cancino-Diaz J and Rodriguez-Martinex S. 2016 L. monocytogenes induces overexpression of proinflammatory IL-36 cytokines in a murine model of early pregnancy. Journal of Reproductive Immunology 11555.

[39] Southcombe J, Redman C, Sargent I and Granne I. 2015 Interleukin-1 family cytokines and their regulatory proteins in normal pregnancy and pre-eclampsia. Clinical Experimental Immunology 181 480-490.

[40] Cohn S, Simon T and Roth K. 1992 Use of transgenic mice to map cis-acting elements in the intestinal fatty acid binding protein (Fabpi) that control cell-lineage specific and regional patterns of expression among the duodenal-colonic and crypt-villus aces of gut epithelium. Journal of Cell Biology 119 27-44.

[41] Hegele R. 1998 A review of intestinal fatty acid binding protein gene variation and the plasma lipoprotein response to dietary components. Clinical Biochemistry 31 609-612.

[42] Chase A, Pellagatti A, Singh S, Score J, Tapper W, Lin F, Hoade Y, Bryant C, Trim N, Yip B, Zoi K, Rasi C, Forsberg L, Dumanski J, Boultwood J and Cross N. 2019 PRR14L mutations are associated with chromosome 22 acquired uniparental disomy, age-related clonal hematopoiesis and myeloid neoplasia. Leukemia 33 1184-1194.

[43] Røseth A, Fagerhol M, Aadland E and Schjønsby H. 1992 Assessment of the neutrophil dominating protein calprotectin in feces: a methodologic study. Scandanavian Journal of Gastroenterology 27 793-798.

\section{Audience Discussion}

Bruce Murphy: How do you get the first protein solution that you put on the gel out of the fecal sample?

Erin Curry: For this study, the protein extraction was performed by a commercial service provider, Applied Biomics. They utilized an extraction technique using PBS with sample agitation and ultrafiltration. In a previous related study, I used an ammonium sulfate precipitation method to extract fecal proteins from polar bear fecal sample. The protein is then resuspended in buffer in preparation for gel separation.

Bruce Murphy: I was quite astonished that there's a difference during diapause, because if you look at the uterus during diapause you can't see any difference. When we've hysterectomised animals, we see that the progesterone profile is the same as in an intact animal. The uterus is not contributing any signals, which is maintained by the corpus luteum. So, it surprises me that during diapause there are some differences that you could detect. Is there some communication between the uterus and the embryo during diapause and if there's a real difference, then what's going on?

Erin Curry: I had some reservations about this analysis as well for those reasons, but it seemed worth pursuing because we'd never know otherwise if we didn't try it. We do not know if there is communication during the uterus and embryo during diapause. In brown bears, the presence of glandular luminal glands has been described in the uteri of females with embryos in diapause, but pseudo-pregnant females were not examined for comparison. Ultimately, the goal is to generate temporal profiles to determine precisely when these proteins may increase or decrease relative to 
breeding, implantation, and parturition. etc. From there, we may be able to infer function and understand how these proteins might be involved in diapause.

Unknown questioner: Are you keeping the time constant in the collection of the stool, because bacterial decomposition and other stuff might add to your protein profile? And even seasonal variation like how bacteria grow differently in the seasons and that can affect your 2D-Image.

Erin Curry: Yes, you raise a good question. The fecal samples selected for this analysis were chosen relative to breeding and parturition for each female to capture the two phases of pregnancy of interest- diapause and placental pregnancy. All animals were fed consistent diets throughout the course of the study, so there should not be differences in fecal proteins attributed to diet. We chose a protein extraction method in which included efforts to filter out intact bacterial cells and fibrous material- we hope this would minimize the amount of protein originating from gut flora and diet. Lastly, mink are seasonal in their reproductive events but our control group would have accounted for changes that were seasonally dependent. 